\title{
Evaluation and Ranking of Driver Behavior Factors Related to Road Safety by Applying Analytic Network Process
}

\author{
Danish Farooq ${ }^{1 *}$, Sarbast Moslem ${ }^{1}$ \\ 1 Department of Transport Technology and Economics, Faculty of Transportation and Vehicle Engineering, \\ Budapest University of Technology and Economics, 1111 Budapest, Múegyetem rkp. 3, Hungary \\ * Corresponding author, e-mail: farooq.danish@mail.bme.hu
}

Received: 26 August 2018, Accepted: 04 October 2018, Published online: 28 June 2019

\begin{abstract}
Human behavior has been considered as a key factor in road safety. Mostly drivers involve in risky behaviors that cause road safety issues. The identification and categorization of risky driver behavior factors is very important to solve road safety issues. This study aims to evaluate and rank the most significant driver behavior factors related to road safety using multi criteria decision making applications. Driver Behavior Questionnaire (DBQ) was designed based on Saaty scale by considering the important risky driver behavior factors related to road safety. Twenty experts of transportation engineering department having high driving experience were asked to fill the dynamic questionnaire survey. The analytic network process (ANP) was applied based on pairwise comparisons of driver responses to rank the risky driver behavior factors. Network model results were used to differentiate more significant and less significant risky driving behavior factors based on measured criteria on perceived road safety issues. The analysis results revealed that "driving without alcohol use" was the most significant factor and "obeying speed limits" was the least significant factor for road safety as compared to other factors. The high rank risky driver behavior factors should be more focused to solve road safety issues. Keywords

Driver Behavior Questionnaire (DBQ), road safety issues, Multi Criteria Decision Making (MCDM), Analytic Network Process (ANP), Pairwise Comparison Matrix (PCM)
\end{abstract}

\section{Introduction}

Road safety has become a critical issue in emerging and developed countries. A comprehensive evaluation approach must be utilized to investigate the road safety issues due to risky driver behavior. The study intended to highlight the most critical driver behavior factors related to road safety. These factors were ranked by utilizing the Analytic Network Process (ANP). A dynamic questionnaire survey and dynamic analysis was applied to reflect the real-world situation by considering the driver behavior factors and interrelations between the factors (Duleba et al., 2012; Saaty, 1994).

Different driving characteristics in different driving states identified the uncertain and complex attitude of individuals (Lin et al., 2014). Many driver behavior factors were found dynamic, conscious rule violations and errors due to less driving experience while others are the result of inattention, momentary mistakes or failure to perform function, the latter often related to age (Stanton and Salmon, 2009; Wierwille et al., 2002).
Driving behavior identification was considered the most important part in traffic studies to collect useful information generally in three main fields such as road safety analysis, microscopic traffic simulation and Iintelligent Transportation Systems (ITS) (Bifulco et al., 2014). Behavior identification was performed in different disciplines like psychology, physiology and ergonomics by taking natural data. The perspectives of human factors and vehicle dynamics application related to road safety were focused in the study (Plochl and Edelmann, 2007).

Many studies have applied multi criteria decision making applications to evaluate human behavior (Furda and Vlacic, 2011; Korhonen and Wallenius, 1997; Yan and Xiansheng, 2009). A review of road safety models in outsourcing literature showed that many researches proposed approaches based on multi criteria decision making analysis to compute the road safety problems (Haghighat, 2011; Hermans et al., 2008; Nanda and Singh, 2018; Shi, 2009). Some studies utilized a multi criteria decision making 
analysis for road safety performance evaluation (Bao et al., 2012; Rosić et al., 2017).

The study focused on the fundamental factors solely related to road safety. It was observed that human factors have the most considerable impact on accident risk. The basic factors which directly influence on road safety were noticed such as driving behavior, driving experience and driver perception of traffic risks (De Ona et al., 2014).

The survey study measured self-reported frequency of drivers involving in a range of driving attitudes and perceived risks. The main questionnaire was formed by considering twelve behavior factors related to road safety issues such as human errors, traffic rules violations and driving after drinking etc. For each behavior, the respondent selected answer on a 5-point scale from "Never" to "Always" that how frequently they involved in the behavior when driving (Rhodesa and Pivikc, 2011). The study used the reckless driving habits scale to observe the self-reported frequency of careless driving. The scale consists of 8 risky driving items, each representing a distinctive type that might hazardous for life or well-being of the driver, pedestrians, passengers and/or passengers of other vehicles. Drivers participated in survey were asked to respond how often they drive in the way defined on a 6-point scale ranging from 1 (never) to 6 (always). The participant responses were averaged to generate a reckless driving habits score, with higher scores representing a higher frequency of reckless driving (Taubman - Ben-Ari et al., 2004).

The study found that driving task experience has a statistically major effect on overall driving performance including overtaking and car speed (De Silva et al., 2014). The study investigated that the task of driving can be easy or difficult depending on the momentary task demand of driving and the driver's skill to control his/her vehicle correctly. Experienced drivers were observed more apparent to show possible avoidance of traffic hazard by changing direction, speed, level of caution, center of attention and information communicated to other road users (Fuller, 2005). Professional drivers were observed to have improved performance on complex road sections than non-professional drivers. In fact, the professional drivers' have high driving time and mileage practice to generate better skills and knowledge of vehicle control (Yan et al., 2014). The study found that the professional drivers drive more cautiously which was facilitated also by the demands of their work (Öz et al., 2010).

The study revealed that drivers with careless driver behavior, excessive speed, chronic fatigue and critical sleepiness may significantly increase the risk of road crashes which can lead to serious injuries (Bener et al., 2017). The study concluded that high traffic volume flow had a significant effect on vehicles conflicts because drivers are more likely to accept shorter gaps at unsignalized intersections (Caird et al., 2008). Road users' risk perception was found essential in the process of driving because it affects driving behavior (Wang et al., 2002). The study investigated the most common causation elements such as faulty prediction or incorrect diagnosis. Automated driving systems are likely to solve the safety problems caused by those factors through perception and sensing technologies. However, risky factors such as unexpected road user behavior, view obstructions and human error by other drivers still pose problems which need further measures to improve road safety (Sandin, 2009).

Most of the previous studies focused only on evaluation of driver behavior items related to road safety. The present study evaluated and ranked the most common driver behavior factors related to road safety issues using multi criteria decision making applications. Driver behavior questionnaire was designed by considering thirteen driver behavior factors which are directly related to road safety. The participants were asked to fill questionnaire on Saaty's ratio scale. The participants were chosen based on their driving experience and their relevant experience in the field of transportation engineering. The filled questionnaire data was analyzed by Analytic Network Process based on pairwise comparisons (PC). The results were utilized to rank the driver behavior factors which have high or less significance related to road safety.

\section{Methodology}

\subsection{Sample}

Driver Behavior Questionnaire (DBQ) was designed to measure risky driver behavior factors related to road safety. The dynamic DBQ included 13 items of risky driving attitudes on Saaty's scale for the convenience of pairwise comparisons (PC). Twenty transportation engineering experts having high driving experience were asked to fill questionnaire for dynamic analysis of road safety issues. Generally, the dynamic analysis utilized real time information and required less amount of data for evaluation purposes. For driver behavior data collection, the participants were approached and interviewed in Budapest university of technology and economics to fill the questionnaire items. The demographic characteristics of respondents related to age, gender and driving experience were mentioned below in Table 1 . 
Table 1 Sample characteristics

\begin{tabular}{lc}
\hline Variables & Data Analysis Results \\
\hline $\mathrm{N}$ & 20 \\
\hline Age & \\
Mean & 42.52857 \\
$\mathrm{SD}$ & 4.25042 \\
\hline Gender $(1=$ male, $0=$ female $)$ & \\
\hline Mean & 0.860563 \\
SD & 0.42977 \\
\hline Driving Experience & \\
\hline Mean & 20.357143 \\
SD & 3.03698 \\
\hline
\end{tabular}

\subsection{Driver behavior factors selection}

Driver behavior has been considered complex and uncertain to study road safety issues. Thirteen driver behavior factors which are mostly considered important in process of driving were selected for the study. The selected driver behaviors factors have direct influence on road safety. These factors are also important for safe movements of drivers themselves and for other road users also. These factors were symbolized from F1 to F13 to make convenience for analysis of ANP approach. The driver behavior factors along with symbols were shown in Table 2.

\subsection{Analytic Network Process application}

Analytic Network Process (ANP) was created by Saaty (1996), which was further utilized as the principal scientific hypothesis to consider the interrelation between the factors (Öztürk, 2006). ANP is a dynamic process that reflects the real situation of complex problems in which factors act in a non-hierarchical way. ANP provides a deeper insight into complex decisions based on pairwise comparisons rather than simple statistical survey (Saaty, 1994).

In this study, the ANP approach was applied to rank the most significant driver behavior factors related to road safety. Twenty transportation engineering experts having high driving experience participated in the designed ANP questionnaire in Budapest city, Hungary. Because of a nonhierarchical acting of the factors, the ANP approach was used to analyze interrelationship between factors.

According to ANP approach, the first step of the analysis consists of filling the pairwise comparison matrices (PCM). The factors level of PCs in ANP was set. In PCs, a ratio scale of 1-9 (Saaty, 1977) was used by evaluators. The fundamental ratio scale consists of numerical values which provide different sorts of information as shown in Table 3. For example, digit one represents equal
Table 2 Driver behavior's factors related to road safety

\begin{tabular}{lc}
\hline Factors & Description \\
\hline F1 & Driver attention \\
F2 & Driver visual perception \\
F3 & Obeying speed limits \\
F4 & Use personal intelligent assistant \\
F5 & Respect yielding/priority rules \\
F6 & Maintain safe gap between vehicles \\
F7 & Avoid frequently changing lanes \\
F8 & Comply traffic lights/signals \\
F9 & Applying brakes at hazardous situations \\
F10 & Deterrence of punish for traffic violations \\
F11 & Traffic scan accurately \\
F12 & Obeying overtaking rules \\
F13 & Driving without alcohol use \\
\hline
\end{tabular}

Table 3 Judgment scale of relative importance for pairwise comparison (Saaty's scale)

\begin{tabular}{|c|c|c|}
\hline $\begin{array}{l}\text { Numerical } \\
\text { values }\end{array}$ & Verbal scale & Explanation \\
\hline 1 & $\begin{array}{l}\text { Equal importance of both } \\
\text { elements }\end{array}$ & $\begin{array}{l}\text { Two elements contribute } \\
\text { equally }\end{array}$ \\
\hline 3 & $\begin{array}{l}\text { Moderate importance of } \\
\text { one element over another }\end{array}$ & $\begin{array}{l}\text { Experience and judgment } \\
\text { favor one element over } \\
\text { another }\end{array}$ \\
\hline 5 & $\begin{array}{l}\text { Strong importance of one } \\
\text { element over another }\end{array}$ & $\begin{array}{l}\text { An element is strongly } \\
\text { favored }\end{array}$ \\
\hline 7 & $\begin{array}{l}\text { Very strong importance } \\
\text { of one element over } \\
\text { another }\end{array}$ & $\begin{array}{l}\text { An element is very } \\
\text { strongly dominant }\end{array}$ \\
\hline 9 & $\begin{array}{l}\text { Extreme importance of } \\
\text { one element over another }\end{array}$ & $\begin{array}{c}\text { An element is favored } \\
\text { by at least an order of } \\
\text { magnitude }\end{array}$ \\
\hline $2,4,6,8$ & Intermediate values & $\begin{array}{l}\text { Used to compromise } \\
\text { between two judgments }\end{array}$ \\
\hline
\end{tabular}

importance of both elements and digit nine represents extreme importance of one element over another.

The consistency analysis of selected factors in super matrix was examined by applying Saaty's Consistency Index $(C I)$ as shown in Fig. 1 and its formula written here:

$C I=\frac{\lambda_{\max }-n}{n-1}$

where $C I$ is the consistency index, $\lambda_{\max }$ is the maximum eigenvalue and $n$ is the number of rows in the matrix. Consistency Ratio (CR) (Saaty, 1977; 2005) was determined as follow.

$C R=\frac{C I}{R I}$ 
where $R I$ is the random consistency index. If $\mathrm{A}$ is a consistency matrix in relation with vector $\mathrm{W}$ depicted as $\mathrm{A} \cdot \mathrm{W}=\lambda_{\max } \cdot \mathrm{W}$. Then eigenvector $\mathrm{W}$ can be calculated as $\left(\mathrm{A}-\lambda_{\max }\right) \cdot \mathrm{W}=0$, where $\lambda_{\text {max }}$ is the maximum eigenvalue of the matrix A. $\lambda_{\max }$ is also known the principal eigenvalue of the matrix A. The threshold was also determined by Saaty, the PCM can be considered as acceptable from inconsistency point of view if $C R<0.1$.

Numerous studies introduced several evaluators but the most accepted aggregation process of AHP was applied here. The geometric mean (Aczél and Saaty, 1983) of the respective evaluator scores for generating aggregated matrices of these values was determined as:

if " $h$ " evaluators exist in the procedure

$$
f\left(x_{1}, x_{2}, \ldots, x_{n}\right)=\sqrt[h]{\prod_{k=1}^{h} x_{a i j k}}
$$

where $a_{i j k}$ denotes the $a_{i j}$ element of the evaluator " $k$ ".

After generating the aggregated matrices, the driving weight vector scores was further determined in the procedure. For measuring the eigenvectors of the aggregate matrices, the following method was applied as:

$$
w_{A i}=\frac{w_{j}}{w} \frac{w_{i j}}{\sum_{k=1}^{n} w_{i k}}=\left(\frac{w_{j}}{w} \frac{1}{\sum_{k=1}^{n} w_{i k}}\right) w_{i j}
$$

where $j=1, \ldots, m$ and $w_{j}>0(j=1, \ldots, m)$ represents the related weight coordinate from the previous level; $w_{i j}>0$ is the eigenvector computed from the matrix in the current level $(i=1, \ldots, n), w_{A i}$ is the calculated weight score of current level's elements $(i=1, \ldots, n)$. The consistency ratio (CR) was acceptable to perform ANP analysis.

The main eigenvector of each PCM represented the synthesis of the numerical judgments established at each level of the network (Saaty, 1980). In the applied approach all the results were determined by using the Super decision software.

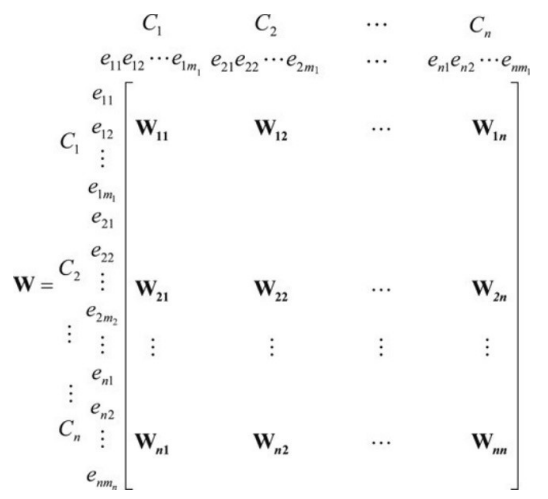

Fig. 1 Super matrix of the analytic network process (Saaty, 2005)

\section{Results and discussion}

Driver behavior questionnaire data was utilized to analyze driver behavior factors related to road safety by ANP approach. Based on pairwise comparisons, the interrelations between driver behavior factors were measured and compared. The hybrid model of driver behavior was structured regarding the dynamic questionnaire survey. The structure of the driver behavior model was described by its factors and by the interaction between examined factors. The interrelations between examined factors (represented by symbols) were shown in Fig. 2. These interrelations indicated the flow of influence between the factors. It was observed that mostly relations between factors were strongly interrelated and only few factors were not interrelated. Total seventy-eight (78) comparisons were observed between factors in which fifty-eight $(78-20=58)$ relations were interrelated and twenty relations were not interrelated.

ANP method was applied to rank the driver behavior factors based on driver responses on driver behavior questionnaire. Super Decisions software was applied to get preference ranking for driver factors related to road safety. Pairwise comparison was used as a tool to rank a set of decision-making criteria and rate the criteria on a relative scale of importance. In pairwise comparison method the criteria were arranged in square matrix.

The pairwise comparison method was further utilized to assign each criteria a quantitative weight. Based on the measured parameters such as normalized weight and idealized weight the driver behavior factors were ranked from one to thirteen as shown in Table 4. The analysis of results showed that "driving without alcohol use" was the most important factor based on expert's response data. Also, according to Hungarian driving laws there is zero tolerance policy towards drinking and driving (WHO, 2015). The second rank factor observed was "obeying

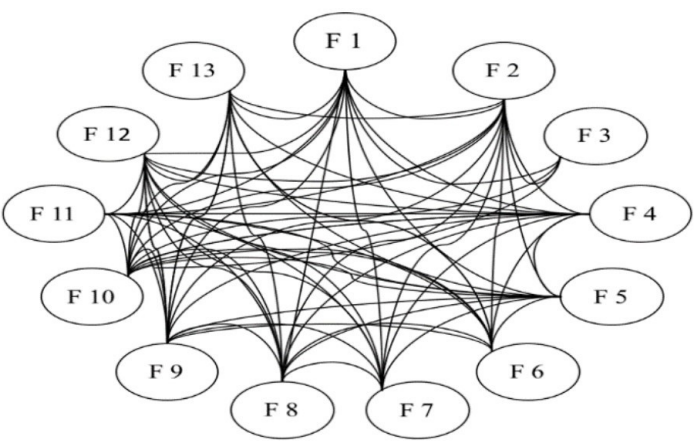

Fig. 2 The network model of driver behavior's factors related to road safety 
Table 4 Ranking of driver behavior's factors related to road safety by evaluators

\begin{tabular}{lccc}
\hline Factor & Normalized Weight & Idealized Weight & Rank \\
\hline F 1 & 0.0983 & 0.43683 & 4 \\
F 2 & 0.0514 & 0.2284 & 9 \\
F 3 & 0.0267 & 0.1187 & 13 \\
F 4 & 0.0617 & 0.2744 & 6 \\
F 5 & 0.0704 & 0.3128 & 5 \\
F 6 & 0.0411 & 0.1827 & 11 \\
F 7 & 0.0601 & 0.2669 & 7 \\
F 8 & 0.0475 & 0.2112 & 10 \\
F 9 & 0.0407 & 0.1810 & 12 \\
F 10 & 0.0989 & 0.4393 & 3 \\
F 11 & 0.0587 & 0.2607 & 8 \\
F 12 & 0.1188 & 0.5278 & 2 \\
F 13 & 0.2251 & 1 & 1 \\
\hline
\end{tabular}

overtaking rules", followed by subsequent factors such as "deterrence of punish for traffic violations", "driver attention" and "respect yielding/priority rules". The analysis results also showed that "obeying speed limits" was the lowest rank factor. Previous study results also showed that mostly Budapest young drivers respected the speed limit rules with less percentage as compared to other road safety factors (Farooq and Juhasz, 2018). Subsequently the other low rank observed factors were "applying brakes at hazardous situations", "maintain safe gap between vehicles" and "comply traffic lights/signals". These preferences make decisions more flexible to solve the variety of road safety problems.

\section{Conclusion}

The study was designed to use one of the multi criteria decision making technique for evaluation and ranking the driver behavior's factors related to road safety. Most common driver behavior factor were selected which have direct influence on road safety. The self-reported questionnaire survey was formed by considering risky driving attitudes based on Saaty's scale for the convenience of pairwise

\section{References}

Aczél, J., Saaty, T. L. (1983) "Procedures for synthesizing ratio judgments", Journal of Mathematical Psychology, 27(1), pp. 93-102. https://doi.org/10.1016/0022-2496(83)90028-7

Bao, Q., Ruan, D., Shen, Y., Hermans, E. (2012) "Improved hierarchical fuzzy TOPSIS for road safety performance evaluation", Knowledge-Based Systems, 32, pp. 84-90. https://doi.org/10.1016/j.knosys.2011.08.014 comparisons (PC). Car drivers having high driving experience were asked to fill driver behavior questionnaire. ANP approach was utilized to evaluate interrelations between factors. Model results showed that most of factors were interrelated to each other while only few factors were not interrelated. The Analytic Network Process was further utilized to rank the driver behavior factors related to road safety. Pairwise comparison was used as a tool to rank a set of decision-making criteria and rate the criteria on a relative scale of importance. In pairwise comparison method the observed factors were arranged in square matrix. The pairwise comparison method was used to assign each criteria a quantitative weight in such a way to satisfy the rank quantitatively. For this purpose, the normalized weight and idealized weigh values were calculated for each factor. Based on these measurements it was analyzed that which behavior factors have high or low significance for road safety. The results showed that "driving without alcohol use" was most significant driver behavior factor based on driver expert's response on driver behavior questionnaire. So, it was observed rank one factor from all other factors. The other two high rank behavior factors observed were "deterrence of punish for traffic violations" and "obeying overtaking rules". The results also showed that "obeying speed limits" was least important factor based on driver responses. So, this factor was observed rank thirteen from all other factors. The other two low rank behavior factors observed were "avoid frequently changing lanes" and "applying brakes at hazardous situation". Similarly, other driver behavior factors have their own ranking.

ANP questionnaire survey is quite complicated and require long time. However, the results represent the real importance of each factor by considering the interrelations between all examined factors. The application enables the decision-makers to better understand the complex relationships of the relevant factors in the decision-making and subsequently improves the reliability of the decision. There is further work needed on different driver groups to analyze road safety issues categorically.

Bener, A. B., Yildirim, E., Ozkan, T. (2017) "Driver sleepiness, fatigue, careless behavior and risk of motor vehicle crash and injury: Population based case and control study", Journal of Traffic and Transportation engineering (English edition), 4(5), pp. 496-502. https://doi.org/10.1016/j.jtte.2017.07.005

Bifulco, G. N., Galante, F., Pariota, L. (2014) "Data Collection for Traffic and Drivers' Behavior Studies: a large-scale survey", Procedia Social and Behavioral Sciences, 111, pp. 721-730. https://doi.org/10.1016/j.sbspro.2014.01.106 
Caird, J. K., Willness, C. R., Steel, P. (2008) "A meta-analysis of the effects of cell phones on driver performance", Accident Analysis and Prevention, 40(4), pp. 1282-1293.

https://doi.org/10.1016/j.aap.2008.01.009

Da Silva, F. P., Santos, J. A., Meireles, A. (2014) "Road accident: Driver behavior, learning and driving task", Procedia - Social and Behavioral Sciences, 162, pp. 300-309.

https://doi.org/10.1016/j.sbspro.2014.12.211

De Oña, J., De Oña, R., Eboli, L. (2014) "How to identify the key factors that affect driver perception of accident risk, A comparison between Italian and Spanish driver behavior", Accident Analysis and Prevention, 73, pp. 225-235.

https://doi.org/10.1016/j.aap.2014.09.020

Duleba, S., Mishina, T., Shimazaki, Y. (2012) "A dynamic analysis on public bus transport's supply quality by using AHP", Transport, 27 (3), pp. 268-275.

https://doi.org/10.3846/16484142.2012.719838

Farooq, D., Juhasz, J. (2018) "Analysis of young driver behavior related to road safety issues in Pakistan and Hungary", In: Proceedings of the 3rd World Congress on Civil, Structural, and Environmental Engineering (CSEE'18), Budapest, Hungary, pp. ICTE 109-1-7. https://doi.org/10.11159/icte18.109

Fuller, R. (2005) "Towards a general theory of driver behavior", Accident Analysis \& Prevention, 37(3), pp. 461-472. https:/doi.org/10.1016/j.aap.2004.11.003

Furda, A., Vlacic, L. (2011) "Enabling safe autonomous driving in real-world city traffic using multiple criteria decision making", Intelligent Transportation Systems Magazine, 3(1), pp. 4-17. https://doi.org/10.1109/MITS.2011.940472

Haghighat, F. (2011) "Application of a multi-criteria approach to road safety evaluation in the Bushehr Province, Iran", PROMET Traffic \& Transportation, 23(5), pp. 341-352. https://doi.org/10.7307/ptt.v23i5.152

Hermans, E., Van den Bossche, F., Wets, G. (2008) "Combining road safety information in a performance index", Accident Analysis \& Prevention, 40(4), pp. 1337-1344. https://doi.org/10.1016/j.aap.2008.02.004

Korhonen, P., Wallenius, J. (1997) "Behavioral issues in MCDM: Neglected research questions", Multi-Criteria Decision Analysis, 5(3), pp. 178-182.

https://doi.org/10.1002/(SICI)1099-1360(199609)5:3\%3C178::AIDMCDA123\%3E3.0.CO;2-P

Lin, N., Zong, C., Tomizuka, M., Song, P., Zhang, Z., Li, G. (2014) "An overviewon study of identification of driver behavior characteristics for automotive control", Mathematical problems in engineering, 2014, Article ID 569109, p. 15.

https:/doi.org/10.1155/2014/569109

Nanda, S., Singh, S. (2018) "Evaluation of factors responsible for road accidents in India by Fuzzy AHP", In: Perez, G., Mishra, K., Tiwari, S., Trivedi, M. (eds.) Networking Communication and Data Knowledge Engineering, Lecture Notes on Data Engineering and Communications Technologies, Vol. 3, Springer, Singapore, pp. 179-188.

https://doi.org/10.1007/978-981-10-4585-1_15
Öz, B., Özkan, T., Lajunen, T. (2010) "Professional and non-professional drivers' stress reactions and risky driving", Transportation Research Part F, 13, pp. 32-40. https://doi.org/10.1016/j.trf.2009.10.001

Öztürk, Z. K. (2006) "A review of multi criteria decision making with dependency between criteria", Multi-Criteria Decision Making, 5, pp. 19-29.

Plochl, M., Edelmann, J. (2007) "Driver models in automobile dynamics application", Vehicle System Dynamics, 45(7-8), pp. 699-741. https://doi.org/10.1080/00423110701432482

Rhodesa, N., Pivikc, K. (2011) "Age and gender differences in risky driving: The roles of positive affect and risk perception", Accident Analysis and Prevention, 43(3), pp. 923-931. https://doi.org/10.1016/j.aap.2010.11.015

Rosić, M., Pešić, D., Kukić, D., Antić, B., Bozovic, M. (2017) "Method for selection of optimal road safety composite index with examples from DEA and TOPSIS method", Accident Analysis \& Prevention, 98, pp. 277-286. https://doi.org/10.1016/j.aap.2016.10.007

Saaty T. L. (1977) "A scaling method for priorities in hierarchical structures", Journal of Mathematical Psychology, 15(3), pp. 234-281. https://doi.org/10.1016/0022-2496(77)90033-5

Saaty, T. L. (1980) "The Analytic Hierarchy Process", McGraw Hill, New York, USA.

Saaty, T. L. (1994) "How to make decision: The analytic hierarchy process", Interfaces, 24(6), pp. 19-43. [online] Available at: https:// www.jstor.org/stable/25061950 [Accessed: 14 August 2018]

Saaty, T. L. (1996) "Decision making with dependence and feedback: The Analytic Network Process", Springer, Boston, MA, USA. https://oi.org/10.1007/978-1-4614-7279-7

Saaty, T. L. (2005) "Theory and Applications of the Analytic Network Process", RWS Publications, Pittsburgh.

Sandin, J. (2009) "An analysis of common patterns in aggregated causation charts from intersection crashes", Accident Analysis and Prevention, 41(3), pp. 624-632. https://doi.org/10.1016/j.aap.2009.02.015

Shi, H. (2009) "Fuzzy evaluation approach of road traffic safety based on AHP", In: 2009 International Conference on Future BioMedical Information Engineering (FBIE), Sanya, China, pp. 394-397. https://doi.org/10.1109/FBIE.2009.5405832

Stanton, N. A., Salmon, P. M. (2009) "Human error taxonomies applied to driving: generic driver error taxonomy and its implications for intelligent transport systems", Safety Science, 47(2), pp. 227-237. https://doi.org/10.1016/j.ssci.2008.03.006

Taubman - Ben-Ari, O., Mikulincer, M., Iram, A. (2004) "A multi-factorial framework for understanding reckless driving - appraisal indicators and perceived environmental determinants", Transportation Research Part F: Traffic Psychology and Behavior, 7(6), pp. 333-349. https:/doi.org/10.1016/j.trf.2004.10.001

Wang, B., Hensher, D. A., Ton, T. (2002) "Safety in the road environment: A driver behavioral response perspective", Transportation, 29(3), pp. 253-270. https://doi.org/10.1023/A:1015661008598 
World Health Organization (WHO) (2015) "Global status report on road safety", [online] Available at: https://www.who.int/violence_injury_ prevention/road_safety_status/2015/en/ [Accessed: 05 August 2018]

Wierwille, W. W., Hanowski, R. J., Hankey, J. M. (2003) "Identification and evaluation of driver errors: overview and recommendations", U.S Department of Transportation, Federal Highway Administration, USA, Rep. FHWA-RD-02-003. [online] Available at: https://rosap.ntl.bts.gov/view/dot/922 [Accessed: 27 July 2018]
Yan, L., Xiansheng, L. (2009) "Traffic safety evaluation in the rural-urban continuum based on ANP", In: 2009 Second International Conference on Intelligent Computation Technology and Automation, Changsha, Hunan, pp. 853-858. https://doi.org/10.1109/ICICTA.2009.672

Yan, X., Li, X., Liu, Y., Zhao, J. (2014) "Effects of foggy conditions on drivers' speed control behaviors at different risk levels", Safety Sciences, 68, pp. 275-287.

https://doi.org/10.1016/j.ssci.2014.04.013 